\title{
Delta Cell of the Pancreas
}

National Cancer Institute

\section{Source}

National Cancer Institute. Delta Cell of the Pancreas. NCI Thesaurus. Code C38639.

A type of cell in the pancreatic islets that secretes somatostatin. 